\title{
Altered hormonal and autonomic nerve responses to hypo- and hyperglycaemia are found in overweight and insulin-resistant individuals and may contribute to the development of type 2 diabetes
}

\author{
Martin H. Lundqvist ${ }^{1}$ (D) $\cdot$ Kristina Almby $^{1}$ (D) Urban Wiklund $^{2}$ (D) Niclas Abrahamsson $^{1}$ (D) Prasad G. Kamble $^{1}$ (D) \\ Maria J. Pereira ${ }^{1}$ (D) Jan W. Eriksson ${ }^{1}$ (D)
}

Received: 16 June 2020 / Accepted: 1 October 2020 / Published online: 26 November 2020

(C) The Author(s) 2020

\begin{abstract}
Aims/hypothesis Results from animal models and some clinical work suggest a role for the central nervous system (CNS) in glucose regulation and type 2 diabetes pathogenesis by modulation of glucoregulatory hormones and the autonomic nervous system (ANS). The aim of this study was to characterise the neuroendocrine response to various glucose concentrations in overweight and insulin-resistant individuals compared with lean individuals.

Methods Overweight/obese ( $\mathrm{HI}, n=15$, BMI $\geq 27.0 \mathrm{~kg} / \mathrm{m}^{2}$ ) and lean $\left(\mathrm{LO}, n=15\right.$, BMI $<27.0 \mathrm{~kg} / \mathrm{m}^{2}$ ) individuals without diabetes underwent hyperinsulinaemic euglycaemic-hypoglycaemic clamps and hyperglycaemic clamps on two separate occasions with measurements of hormones, Edinburgh Hypoglycaemic Symptom Scale (ESS) score and heart rate variability (HRV). Statistical methods included groupwise comparisons with Mann-Whitney $U$ tests, multilinear regressions and linear mixed models between neuroendocrine responses and continuous metabolic variables.

Results During hypoglycaemic clamps, there was an elevated cortisol response in HI vs LO (median $\Delta$ AUC 12,383 vs $4793 \mathrm{nmol} / \mathrm{l} \times \mathrm{min} ; p=0.050)$ and a significantly elevated adrenocorticotropic hormone (ACTH) response in HI vs LO (median $\triangle$ AUC 437.3 vs $162.0 \mathrm{nmol} / 1 \times \min ; p=0.021)$. When adjusting for clamp glucose levels, obesity $(p=0.033)$ and insulin resistance $(p=0.009)$ were associated with elevated glucagon levels. By contrast, parasympathetic activity was less suppressed in overweight individuals at the last stage of hypoglycaemia compared with euglycaemia (high-frequency power of HRV, $p=$ 0.024). $M$ value was the strongest predictor for the ACTH and $\mathrm{P}_{\mathrm{HF}}$ responses, independent of BMI and other variables. There was a BMI-independent association between the cortisol response and ESS score response $(p=0.024)$. During hyperglycaemic clamps, overweight individuals displayed less suppression of glucagon levels (median $\Delta$ AUC $-63.4 \%$ vs $-73.0 \% ; p=0.010$ ) and more suppression of sympathetic relative to parasympathetic activity (low-frequency/high-frequency power, $p=0.011$ ).

Conclusions/interpretation This study supports the hypothesis that altered responses of insulin-antagonistic hormones and the ANS to glucose fluctuations occur in overweight and insulin-resistant individuals, and that these responses are probably partly mediated by the CNS. Their potential role in development of type 2 diabetes needs to be addressed in future research.
\end{abstract}

Jan W. Eriksson

jan.eriksson@medsci.uu.se

1 Department of Medical Sciences, Uppsala University, Uppsala, Sweden

2 Department of Radiation Sciences, Biomedical Engineering, Umeå University, Umeå, Sweden 


\section{Research in context}

\section{What is already known about this subject?}

- Hypoglycaemia elicits secretion of counter-regulatory hormones (glucagon, cortisol, catecholamines and growth hormone) and activation of the autonomic nervous system, which collectively act to raise glucose levels

- The central nervous system plays a role in type 2 diabetes pathogenesis

\section{What is the key question?}

- How does obesity affect the counter-regulatory hormonal and autonomic nervous system response at a broad range of glucose concentrations?

\section{What are the new findings?}

- Overweight insulin-resistant individuals have an increased central activation of the cortisol axis during hypoglycaemia, compared with lean individuals, and this is also associated with more pronounced hypoglycaemic symptoms

- Insulin resistance is a stronger predictor of the cortisol axis response than obesity

How might this impact on clinical practice in the foreseeable future?

- Further research on the neurocircuits and endocrine pathways involved can deliver new concepts for precision medicine in type 2 diabetes

Keywords ACTH · Central nervous system - Cortisol · Diabetes · Glucoregulatory hormones · Glucose · Insulin resistance · Obesity

$\begin{array}{ll}\text { Abbreviations } \\ \text { ACTH } & \text { Adrenocorticotropic hormone } \\ \text { ANS } & \text { Autonomic nervous system } \\ \text { CNS } & \text { Central nervous system } \\ \text { ESS } & \text { Edinburgh Hypoglycaemia Symptom Scale } \\ \text { FFM } & \text { Fat-free mass } \\ \text { GIR } & \text { Glucose infusion rate } \\ \text { HRV } & \text { Heart rate variability } \\ \text { LO } & \text { Lean } \\ \text { HI } & \text { Non-diabetic overweight/obese } \\ \mathrm{P}_{\mathrm{HF}} & \text { High-frequency power } \\ \mathrm{P}_{\mathrm{LF}} & \text { Low-frequency power } \\ \mathrm{P}_{\mathrm{TOT}} & \text { Total spectral power }\end{array}$

\section{Introduction}

Since the 19th century, our understanding of glucose regulation and the pathogenesis of diabetes has mainly been based on processes in peripheral tissues, in particular the islets of Langerhans in the pancreas and target organs of insulin action such as the liver, muscle and adipose tissue. The ability of beta cells to detect and respond to varying glucose concentrations by modulating the secretion of insulin has long been considered as the major factor maintaining glucose homeostasis and explaining glucose dysregulation in diabetes. However, the importance of other glucose-regulating hormones, most notably glucagon, in diabetes development has been increasingly emphasised [1].

Hypoglycaemia elicits a typical response consisting of secretion of counter-regulatory hormones (glucagon, cortisol, catecholamines and growth hormone) and activation of the autonomic nervous system (ANS), which collectively act to raise glucose levels [2, 3]. Dysregulation in some of these hormonal and neural systems has been demonstrated in type 2 diabetes, prediabetes and obesity, suggesting a possible role in the development of type 2 diabetes [4-10].

Besides a relative insulin deficiency, hyperglucagonaemia is another hallmark of type 2 diabetes in humans. This has most clearly been demonstrated postprandially [4-6], whereas evidence of hyperglucagonaemia during fasting and experimental hypoglycaemia in obesity and type 2 diabetes is conflicting [7, 8, 11-14]. A biphasic glucagon response to different glucose levels has been described in mouse islets in vitro, with increased secretion in hyperglycaemic as well as hypoglycaemic conditions [15] but there is no evidence of this phenomena in human islets to our knowledge. The response of cortisol, adrenocorticotropic hormone (ACTH) and catecholamines to hypoglycaemia is reportedly, albeit inconsistently, augmented in obesity and/or type 2 diabetes, whereas basal levels have not been significantly different compared with healthy controls $[7-10,16,17]$. The growth 
hormone response to hypoglycaemia, on the other hand, has been consistently shown to be attenuated in obese individuals $[18,19]$. Heart rate variability (HRV) studies have found evidence of lower parasympathetic activity in obesity, insulin resistance and type 2 diabetes, whereas sympathetic activity is not consistently altered [20-22]. The HRV response to hypoglycaemia in obesity and type 2 diabetes vs healthy individuals has not been thoroughly studied.

The brain is highly involved in the coordination of the counter-regulatory response to hypoglycaemia [2] and a 'brain -centric' model for glucose regulation has been proposed by some investigators [23]. According to this model, the brain senses glucose levels and mounts responses to deviations from a setpoint, much like a thermostat. Indeed, neurons that react to both high and low levels of glucose have been identified in the central nervous system (CNS). These neurons are most prevalent in the hypothalamus and the brain stem and project to other neurons involved in the regulation of hormonal axes and ANS activity [10].

We and others have performed hypoglycaemic clamps in obese individuals before and after gastric bypass surgery [24, 25]. After surgery, the responses of counter-regulatory hormones and sympathetic activity were markedly attenuated. Since asymptomatic hypoglycaemia is common after bariatric surgery, one possible explanation for this finding is that there is a post-surgery resetting of glucose regulation towards the hypoglycaemic range. Alternatively, it could reflect a normalisation of an exaggerated counter-regulatory response a priori in obese individuals. Such changes in the 'glycaemic setpoint' might involve altered glucose sensing and regulation by the CNS and may, in the long term, contribute to the development of type 2 diabetes, which is strongly associated with obesity.

In this study, to further elucidate regulation of insulinantagonistic neurohormonal responses, we performed hyperinsulinaemic euglycaemic-hypoglycaemic clamps as well as hyperglycaemic clamps in individuals with varying BMI and degrees of insulin resistance. The objective was to investigate differences in the secretion of glucose-regulating hormones and ANS activity across a broad range of defined glucose concentrations. We also aimed to dissect the impact of obesity, insulin resistance and chronic dysglycaemia, respectively, on the perturbations of these neuroendocrine glucoseregulatory responses.

\section{Methods}

\section{Participants}

This study was conducted at the Uppsala University Hospital and the Department of Medical Sciences at Uppsala University. Participants were aged 18-60 years with a BMI of $18.5-50 \mathrm{~kg} / \mathrm{m}^{2}$. They were recruited by advertisements in newspapers and public spaces, after previously participating in other studies or attending the outpatient obesity unit. Exclusion criteria were as follows: diagnosis of diabetes, endocrine or other diseases that could influence the results or the participants' ability to participate in the study; use of medication with metabolic side effects; planned or ongoing pregnancy; and significant substance abuse. In the recruitment process, we aimed for a wide distribution of BMI. Participants were recruited across a wide range of BMI, aiming to have a representation of lean $\left(18.5-24.9 \mathrm{~kg} / \mathrm{m}^{2}\right)$, overweight or mildly obese $\left(25.0-34.9 \mathrm{~kg} / \mathrm{m}^{2}\right)$ and severely obese $(35.0-50.0 \mathrm{~kg} /$ $\mathrm{m}^{2}$ ) individuals.

\section{Study design}

Participants underwent a stepwise hyperinsulinaemic euglycaemic-hypoglycaemic clamp and a stepwise hyperglycaemic clamp on two occasions separated by $1-$ 5 weeks. The order of the two clamps was randomised 1:1 in blocks of four subjects, and this was not blinded. At each visit, anthropometrics were obtained and body composition was assessed using bioimpedance (Tanita body composition analyzer, BC-418; Tanita Corporation, Tokyo, Japan). Heart rate and HRV were measured during both visits with a custom-made single-channel ECG recording system (developed at Biomedical engineering, R\&D, University Hospital Umeå, Sweden). Baseline blood samples were drawn, after participants had fasted for at least $10 \mathrm{~h}$ overnight at both visits, just before the start of each clamp at approximately 09:00 hours.

The hyperinsulinaemic euglycaemic-hypoglycaemic clamps (henceforth denoted hypoglycaemic clamps), depicted in Fig. 1a, were performed as previously described [26] and modified by our group through previous studies [24]. At $0 \mathrm{~min}$, simultaneous infusions of insulin $\left(56 \mathrm{mU} \mathrm{m}^{-2} \mathrm{~min}^{-1}\right.$ after $10 \mathrm{~min}$ priming), potassium chloride $(8 \mathrm{mmol} / \mathrm{h})$ and glucose $(200 \mathrm{mg} / \mathrm{ml})$ were started. The glucose infusion rate (GIR) was adjusted to initially achieve a glucose level of $5.0 \mathrm{mmol} / 1$ followed by a stepwise lowering towards a nadir of $2.7 \mathrm{mmol} / \mathrm{l}$. At $185 \mathrm{~min}$, the insulin infusion was terminated and glucose was infused at a fixed rate of $200 \mathrm{mg} \mathrm{kg}^{-1} \mathrm{~h}^{-1}$ (recovery phase). The stepwise hyperglycaemic clamp protocol (Fig. 1b) was inspired by previously described two-step hyperglycaemic clamps [27, 28]. A variable glucose infusion ( $200 \mathrm{mg} / \mathrm{ml}$ ) was administered to raise plasma glucose above the fasting level in three steps. At $165 \mathrm{~min}$ the glucose infusion was terminated to allow glucose levels to normalise. Glucose levels were analysed every 5 min during the clamps with blood drawn from an arterialised vein using a Contour Glucose Meter (Bayer Healthcare, Leverkusen, Germany).

During the clamps, hormonal and haemodynamic measurements were obtained at regular intervals. Single-channel ECG recordings were continuously made throughout each clamp. 
a

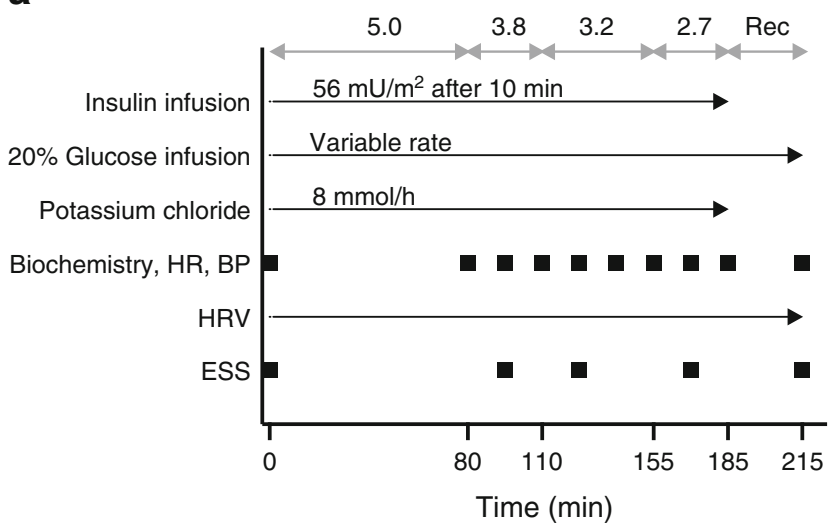

Fig. 1 Clamp procedures during hypoglycaemic (a) and hyperglycaemic (b) clamps. Black squares indicate times at which measurements were taken. Target glucose levels $(\mathrm{mmol} / \mathrm{l})$ are indicated by the grey arrows at b

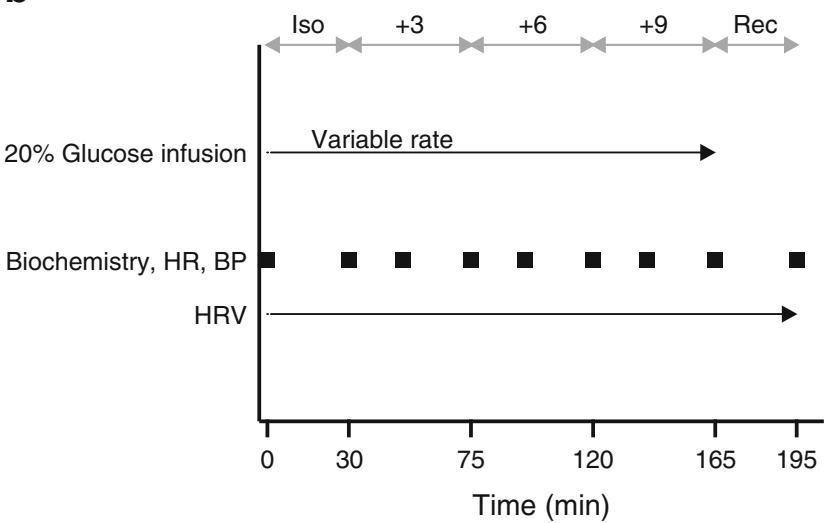

the top. 'Biochemistry' includes concentrations of glucose, glucagon, cortisol, ACTH, growth hormone, NEFA and glycerol; HR, heart rate; Iso, isoglycaemic phase of hyperglycaemic clamp; Rec, recovery
During hypoglycaemic clamps, participants were also asked to assess their hypoglycaemic symptoms according to the Edinburgh Hypoglycaemia Symptom Scale (ESS) [29, 30]. Further details are provided in electronic supplementary material (ESM) Methods.

\section{Biochemical measurements}

Samples were analysed immediately or frozen at $-80^{\circ} \mathrm{C}$ until analysis. Glucagon ELISA, NEFA fluorometric and glycerol colourimetric assays were analysed at the Clinical Diabetes Research Laboratory. All other analyses were performed at the Department of Clinical Chemistry at the Uppsala University Hospital, Sweden using a hexokinase method for glucose and immunoassays for hormones. Details of the analyses are provided in ESM Methods.

\section{HRV analysis}

ECG recordings were automatically processed and manually inspected. The total spectral power $\left(\mathrm{P}_{\mathrm{TOT}}\right)$, low-frequency power $\left(\mathrm{P}_{\mathrm{LF}}, 0.04-0.15 \mathrm{~Hz}\right)$ and high-frequency power $\left(\mathrm{P}_{\mathrm{HF}}\right.$, $0.15-0.50 \mathrm{~Hz})$ were calculated. $\mathrm{P}_{\mathrm{HF}}$ mainly reflects the parasympathetic part of cardiac autonomic modulation, while $\mathrm{P}_{\mathrm{LF}}$ reflects a combination of sympathetic and parasympathetic activity. The ratio $\mathrm{P}_{\mathrm{LF}} / \mathrm{P}_{\mathrm{HF}}$ is used as a proxy for balance between sympathetic and parasympathetic activity [31]. The HRV analysis was performed using Matlab Software version R2019a (MathWorks, Natick, MA, USA). More details are provided in ESM Methods.

\section{Statistical analysis}

This was an exploratory study, and no formal power calculation for sample size selection was performed. The primary endpoint was the glucagon levels during experiments, including hypo- and hyperglycaemia. As estimated from previous studies, there is more than $80 \%$ power to detect $25 \%$ differences in glucagon levels between groups with 15 participants each, assuming an inter-subject CV of 0.20 and a two-sided $\alpha$ of 0.05 ; the same estimate also applies for cortisol levels [24, $25,32-35]$. In the analyses, participants were allocated to two equally large groups, lean (LO) and overweight/obese (HI) with cut-off at the median BMI. Mann-Whitney $U$ tests were consistently used for groupwise comparisons of continuous variables and Fisher's exact test for categorical variables. $p$ values $<0.05$ were considered significant.

Spearman's Rank correlation analyses and multilinear regression analyses were performed on pooled data for all participants between neuroendocrine response variables (hormones and HRV indices) during the hypoglycaemic and hyperglycaemic phases and candidate predictors.

To describe hormonal responses vs achieved glucose levels, scatterplots of hormone levels at the end of each clamp stage vs the mean glucose for the preceding 20 min were used for visual presentation, and linear mixed models were used for statistical inference. All statistical methods are described in detail in ESM Methods.

All analyses were performed in SPSS for Mac version 25 (IBM Corp., Armonk, NY, USA). Figures and graphs were made using GraphPad Prism version 8.3.0 (GraphPad Software, San Diego, CA, USA).

\section{Ethics}

All study procedures were performed in accordance with the Declaration of Helsinki. The local Research Ethics Committee of Uppsala gave their approval (DNR 2017/550). The participants received oral and written information about the study and signed an informed consent form. 


\section{Results}

Thirty participants were included, with a median BMI of $27.0 \mathrm{~kg} / \mathrm{m}^{2}$, defining the cut-off between groups LO and HI. Participant characteristics from visit 1 (baseline) are shown in Table 1. The distribution of sex and age was similar in the groups. Fasting glucose levels were similar in the groups while HI had higher HOMA-IR than LO. One participant in each group had fasting glucose above $7.0 \mathrm{mmol} / \mathrm{l}$ but $\mathrm{HbA}_{1 \mathrm{c}}$ was normal. One participant in $\mathrm{HI}$ did not complete the hyperglycaemic clamp because of problems with maintaining venous access and was omitted from the analysis. For four participants in HI, insulin infusion rates had to be increased during hypoglycaemic clamps because of difficulties in obtaining target glucose levels. HRV analysis was not possible due to imperfect ECG recordings for four participants undergoing hypoglycaemic clamps and two undergoing hyperglycaemic clamps (all group LO), and these participants were omitted from these analyses.

Complete clamp measurements are provided in ESM Tables 1 and 2.

\section{Hypoglycaemic clamps}

Metabolism Glucose levels were higher in HI vs LO during hypoglycaemia, and rose faster during the recovery phase (Fig. 2a and ESM results). The GIR per kg fat-free mass (FFM) was consistently lower in HI vs LO throughout the clamp, and the $M$ value (GIR/FFM from $40 \mathrm{~min}$ to $80 \mathrm{~min}$ ) was significantly lower ( $p=0.007$, Fig. $2 \mathrm{~g}$ and ESM Table 1$)$.

Table 1 Characteristics of participants

\begin{tabular}{|c|c|c|c|}
\hline Variable & LO (BMI $\left.<27.0 \mathrm{~kg} / \mathrm{m}^{2} ; n=15\right)$ & $\mathrm{HI}\left(\mathrm{BMI} \geq 27.0 \mathrm{~kg} / \mathrm{m}^{2} ; n=15\right)$ & $p$ value (HI vs LO) \\
\hline Age, years & $41(30,51)$ & $43(31,54)$ & 0.775 \\
\hline Sex, $n$ male $/ n$ female & $5 / 10$ & $3 / 12$ & 0.682 \\
\hline Weight, $\mathrm{kg}$ & $70.0(59.0,82.0)$ & $97.2(86.1,127.6)$ & $<0.001 * * *$ \\
\hline BMI, $\mathrm{kg} / \mathrm{m}^{2}$ & $23.4(22.5,26.0)$ & $32.0(28.9,45.6)$ & $<0.001 * * *$ \\
\hline Body fat, $\%$ & $22.1(20.7,29.4)$ & $42.0(38.2,51.2)$ & $<0.001 * * *$ \\
\hline Waist/hip ratio & $0.83(0.77,0.90)$ & $0.94(0.90,0.99)$ & $<0.001 * * *$ \\
\hline ESS score & $12(12,17)$ & $13(12,16)$ & 0.713 \\
\hline Resting heart rate, bpm & $60(56,68)$ & $65(56,76)$ & 0.412 \\
\hline Systolic BP, mmHg & $115(110,130)$ & $128(120,135)$ & $0.041 *$ \\
\hline Diastolic BP, mmHg & $78(74,85)$ & $84(78,90)$ & $0.033 *$ \\
\hline $\mathrm{HbA}_{1 \mathrm{c}}, \mathrm{mmol} / \mathrm{mol}$ & $34(31,34)$ & $35(32,37)$ & 0.233 \\
\hline $\mathrm{HbA}_{1 \mathrm{c}}, \%$ & $5.3(5.0,5.3)$ & $5.4(5.1,5.5)$ & 0.233 \\
\hline Fasting plasma glucose, $\mathrm{mmol} / \mathrm{l}$ & $5.5(5.3,5.9)$ & $5.8(5.4,6.2)$ & 0.187 \\
\hline Serum C-peptide, nmol/1 & $0.6(0.5,0.8)$ & $1.1(0.6,1.3)$ & $0.001 * *$ \\
\hline Serum insulin, $\mathrm{pmol} / 1$ & $31.9(24.3,55.6)$ & $79.9(41.0,152.8)$ & $0.001 * *$ \\
\hline HOMA-IR & $1.14(0.86,1.96)$ & $3.27(1.42,5.21)$ & $0.001 * *$ \\
\hline Plasma cholesterol, $\mathrm{mmol} / \mathrm{l}^{\mathrm{a}}$ & $4.6(3.9,5.0)$ & $4.4(3.7,5.2)$ & 0.872 \\
\hline Plasma LDL, mmol/1 & $2.5(2.2,2.7)$ & $2.9(2.4,3.7)$ & 0.067 \\
\hline Plasma HDL, mmol/1 & $1.50(1.20,1.90)$ & $0.91(0.86,1.10)$ & $<0.001 * * *$ \\
\hline Plasma triacylglycerols, mmol/1 & $0.65(0.51,0.76)$ & $0.99(0.72,1.29)$ & $0.009 * *$ \\
\hline Plasma glucagon, pmol/1 & $8.9(6.5,12.3)$ & $10.5(9.0,13.1)$ & 0.486 \\
\hline Serum cortisol, nmol/1 & $257(197,338)$ & $170(127,269)$ & $0.037 *$ \\
\hline Plasma ACTH, pmol/1 & $2.3(2.1,4.4)$ & $2.5(1.8,4.6)$ & 0.775 \\
\hline Plasma GH, $\mu \mathrm{g} / 1$ & $1.08(0.15,4.20)$ & $0.37(0.07,1.06)$ & 0.126 \\
\hline Plasma NEFA, $\mu \mathrm{mol} / 1$ & $182.0(132.7,232.1)$ & $258.6(212.8,553.5)$ & $0.002 * *$ \\
\hline Plasma glycerol, $\mu \mathrm{mol} / 1$ & $63.7(53.2,82.3)$ & $78.7(65.8,102.8)$ & 0.050 \\
\hline
\end{tabular}

Data are presented as median (25th percentile, 75th percentile) and were obtained at the first visit (or second if missing at first)

${ }^{\text {a }}$ Samples are missing for eight participants

${ }^{*} p<0.05, * * p<0.01$ and $* * * p<0.001$

$\mathrm{GH}$, growth hormone 
Fig. 2 Levels of glucose measured by bedside glucometer $(\mathbf{a}, \mathbf{b})$, insulin (c, d), C-peptide (e, f) and GIR/FFM (g, h). Data are presented as geometric means \pm geometric SD $(\mathbf{a}-\mathbf{f})$ and medians \pm IQRs, as well as individual values $(\mathbf{g}, \mathbf{h})$. Data from hypoglycaemic clamps (a, c, e, g) and hyperglycaemic clamps (b, d, f, h) are shown. Target glucose levels $(\mathrm{mmol} / \mathrm{l})$ are indicated by the grey double-headed arrows. Black circles and solid lines, HI (BMI $\geq 27.0 \mathrm{~kg} / \mathrm{m}^{2} ; n=15$ in a, $\mathbf{c}$, $\mathbf{e ,} \mathbf{g}$ and $n=14$ in $\mathbf{b}, \mathbf{d}, \mathbf{f}, \mathbf{h}$ ); white triangles and dashed lines, $\mathrm{LO}$ (BMI $<27.0 \mathrm{~kg} / \mathrm{m}^{2} ; n=15$ in all panels); in (g, h), black circles and bars, $\mathrm{HI}$; white triangles and grey bars, LO. Significance estimates refer to comparisons of the AUC (a-f) or total amount of infused glucose $(\mathrm{g})$ for the indicated time periods between groups $\mathrm{HI}$ and LO: $* p<0.05, * * p<0.01$, $* * * p<0.001$. Groupwise comparison of central laboratory glucose measures gave similar results as for glucometer measures, which are reported here owing to more frequent sampling. Complete measurements are provided in ESM Table 1. Iso, isoglycaemic phase of hyperglycaemic clamp; Rec, recovery a
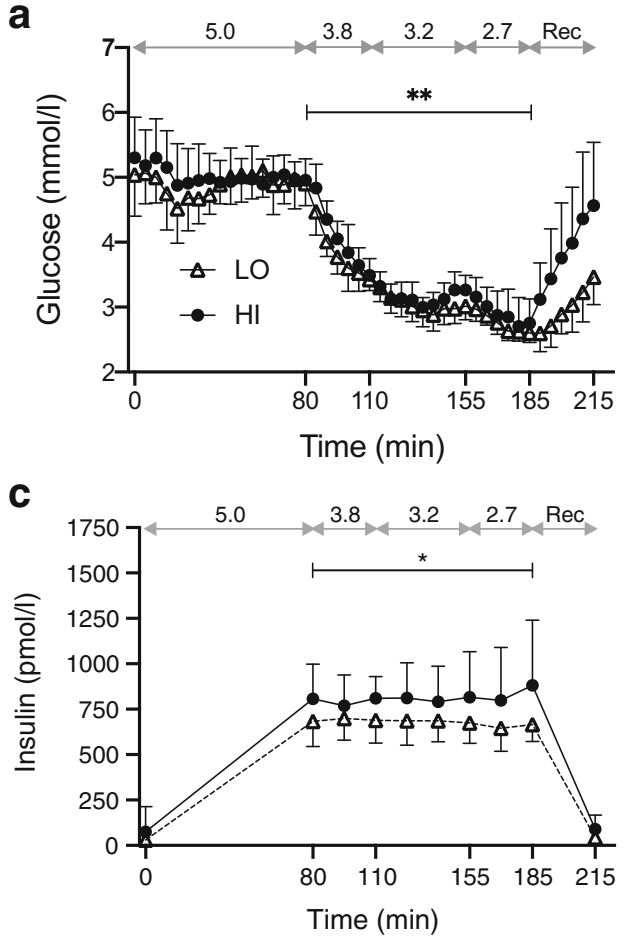

e
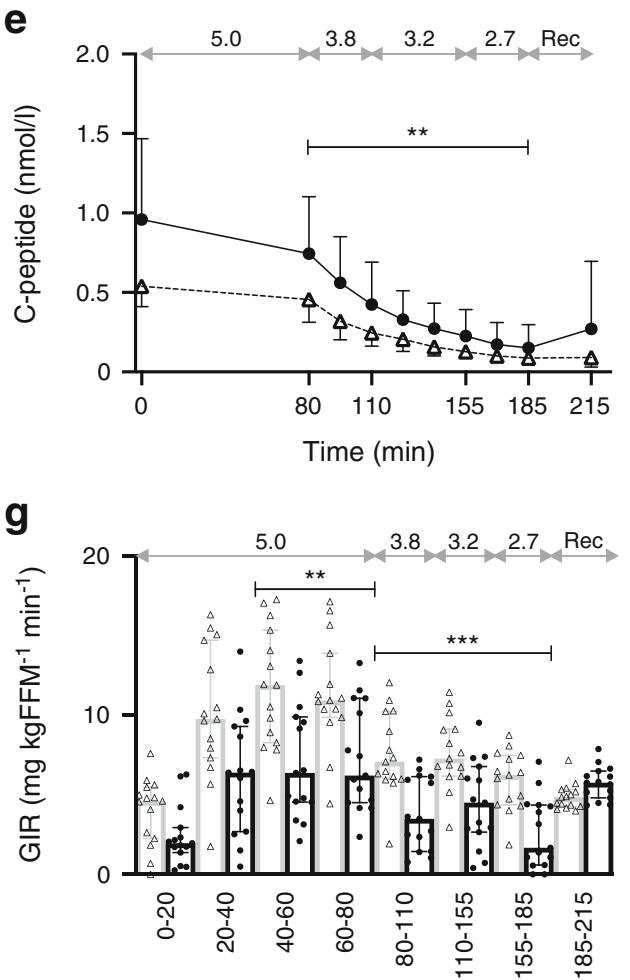

Time (min)

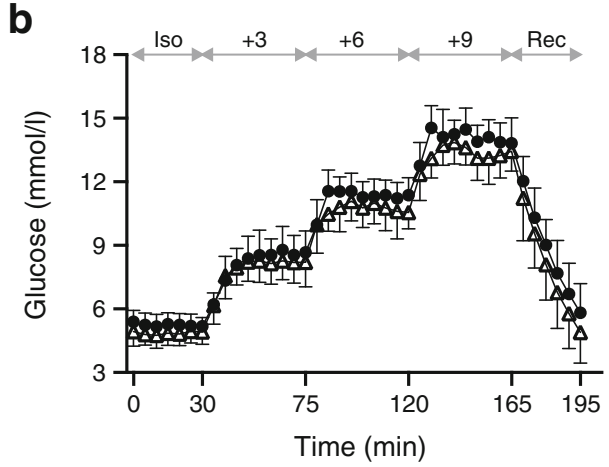

d

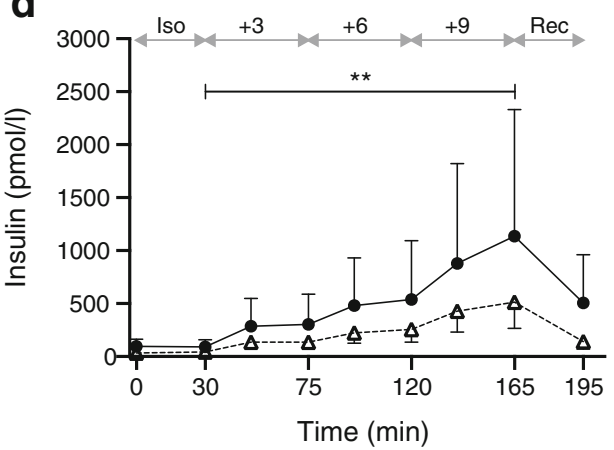

$\mathbf{f}$

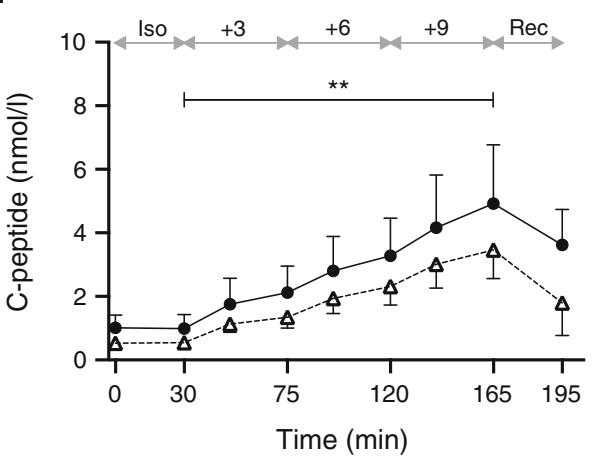

h

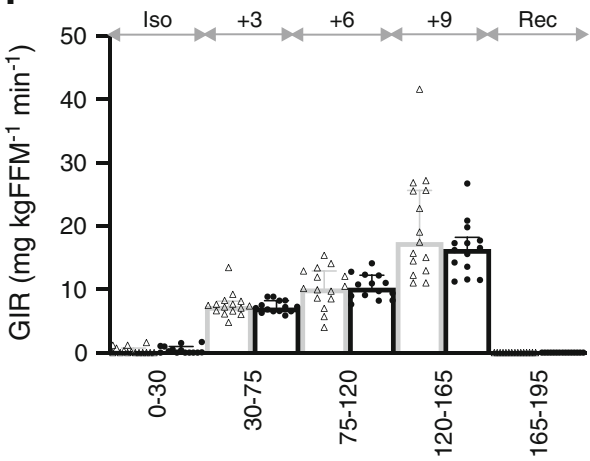

Time (min)
Fasting NEFA $(p=0.002)$ and glycerol $(p=0.050)$ levels were higher in HI vs LO. In both groups, they dropped similarly during hyperinsulinaemia-euglycaemia and then stabilised during hypoglycaemia, with NEFA levels remaining higher $(p=0.004)$ in HI vs LO (Table 1, ESM Table 1).
Hormonal response Insulin and C-peptide levels were higher in HI vs LO (Fig. 2c,e). Glucagon levels did not differ between the groups (Fig. 3a). Cortisol levels were lower at baseline and the change in AUC ( $\triangle \mathrm{AUC})$ was higher in $\mathrm{HI}$ vs LO (median 12,383 vs $4793 \mathrm{nmol} / 1 \times \min ; p=0.050$ ), 
Fig. 3 Levels of counterregulatory hormones. Data are presented as geometric means \pm geometric SD. Data from hypoglycaemic clamps (a, c, e, g) and hyperglycaemic clamps (b, d, f, h) are shown. Target glucose levels $(\mathrm{mmol} / \mathrm{l})$ are indicated by the grey double-headed arrows. Black circles and solid lines, HI (BMI $\geq 27.0 \mathrm{~kg} / \mathrm{m}^{2} ; n=15$ in a, c, $\mathbf{e}, \mathbf{g}$ and $n=14$ in $\mathbf{b}, \mathbf{d}, \mathbf{f}, \mathbf{h}$ ); white triangles and dashed lines, LO (BMI $<27.0 \mathrm{~kg} / \mathrm{m}^{2} ; n=15$ in all panels). Significance estimates refer to comparison of $\triangle \mathrm{AUC}$ (b, $\mathbf{c}, \mathbf{e})$ or AUC (h) between groups HI and LO: $* p<0.05$. Complete measurements are provided in ESM Table 1. GH, growth hormone; Iso, isoglycaemic phase of hyperglycaemic clamp; Rec, recovery
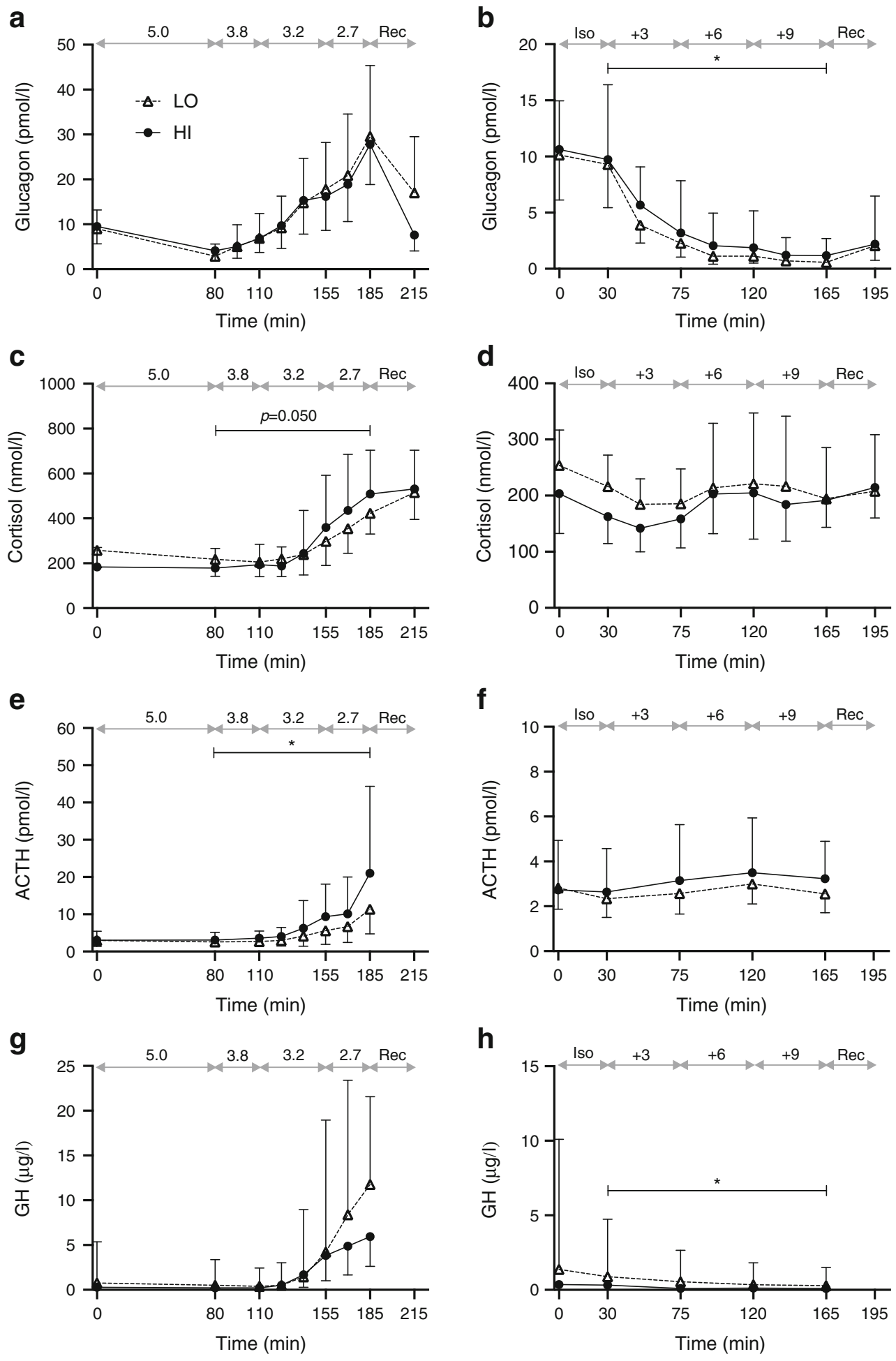

f

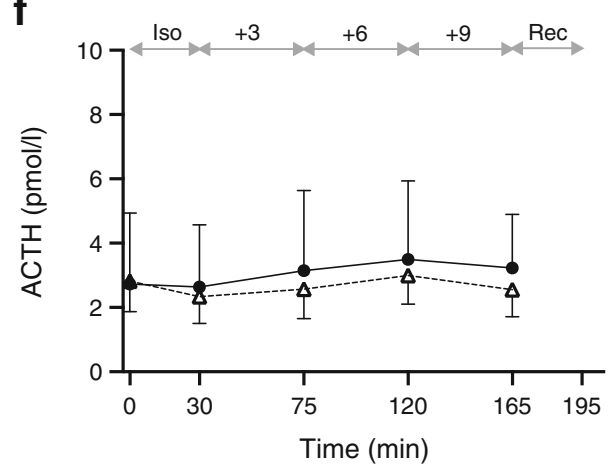

h

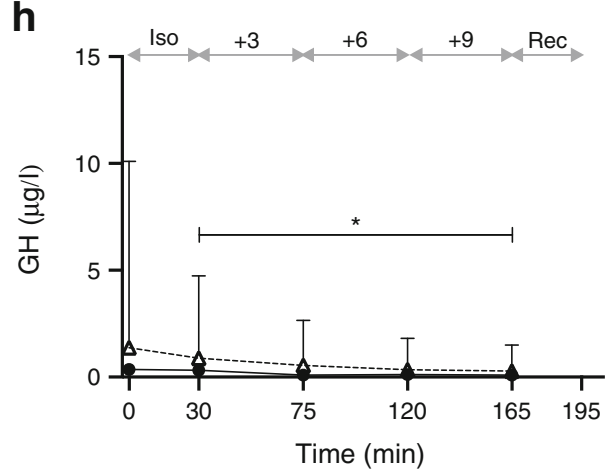

although not significantly (Table 1, Fig. 3c). ACTH did not differ at baseline and rose to higher levels in $\mathrm{HI}$ vs $\mathrm{LO}$ (median $\Delta$ AUC 437.3 vs $162.0 \mathrm{nmol} / \mathrm{l} \times \mathrm{min} ; p=0.021$ ) (Fig. $3 \mathrm{e}$ ). Growth hormone levels were lower in $\mathrm{HI}$ vs LO at baseline $(p=0.126)$ as well as during hypoglycaemia $(p=0.250)$ but the differences were not significant (Table 1, Fig. 3g).
Haemodynamic measurements, $\mathrm{HRV}$ and symptoms Baseline heart rate did not differ between the groups; systolic and diastolic BP were higher in HI but they behaved similarly during the clamps (Table 1, ESM Table 2).

The HRV indices did not differ significantly between the groups during the euglycaemic phase. During hypoglycaemia, 
Table 2 ESS scores during hypoglycaemic clamps

\begin{tabular}{llll}
\hline Measurement & LO & HI & $p$ value (HI vs LO) \\
\hline ESS score & & & \\
$\quad$ Peak & $18(15,25)$ & $21(20,23)$ & 0.126 \\
$\quad \Delta$ Peak-baseline & $5(2,9)$ & $7(5,9)$ & 0.126 \\
Auto & & & \\
$\quad$ Peak & $7(6,14)$ & $11(9,12)$ & 0.217 \\
$\quad \Delta$ Peak-baseline & $2(2,6)$ & $5(2,7)$ & 0.233 \\
Neuro & & & \\
$\quad$ Peak & $8(6,9)$ & $9(7,10)$ & 0.325 \\
$\quad \Delta$ Peak-baseline & $2(2,3)$ & $3(2,4)$ & 0.624 \\
Nausea & & & \\
Peak & $2(2,3)$ & $3(2,4)$ & 0.412 \\
$\quad \Delta$ Peak-baseline & $0(0,1)$ & $1(0,1)$ & 0.567 \\
\hline
\end{tabular}

Data are presented as median (25th percentile, 75 th percentile)

Auto, autonomic domain of ESS; Neuro, neuroglycopenic domain of ESS

compared with euglycaemia, the RR interval, $\mathrm{P}_{\mathrm{TOT}}, \mathrm{P}_{\mathrm{LF}}$ and $\mathrm{P}_{\mathrm{HF}}$ fell to a lesser degree in $\mathrm{HI}$ vs LO and in the last stage of hypoglycaemia there was a significant group difference in all these responses $\left(p=0.024\right.$ for $\left.\mathrm{P}_{\mathrm{HF}}\right)$ (Fig. $4 \mathrm{a}$ and $\mathrm{ESM}$ Table 2). The $\mathrm{P}_{\mathrm{LF}} / \mathrm{P}_{\mathrm{HF}}$ ratio did not, however, differ between the groups (Fig. 4c, ESM Table 2). Participants in HI reported more pronounced symptoms than those in LO but the difference was not significant ( $p=0.126$ for both peak and $\Delta \mathrm{ESS}$ scores; Table 2).

Associations between neuroendocrine responses and metabolic phenotype Main results are displayed in Tables 3, 4 . Scatterplots of $\triangle \mathrm{AUC}$ for glucagon, cortisol and ACTH vs $M$ value are displayed in Fig. 5 (b,d,f).

Both obesity indices and insulin resistance indices were associated with a higher response of the cortisol axis and an HRV response indicative of less parasympathetic suppression. Insulin resistance was also associated with less sympathetic activation. The fasting glucose was correlated only with the HRV responses, in the same direction as obesity and insulin resistance. The growth hormone response only correlated with sex (higher in women). $\triangle$ ESS scores were positively correlated with the cortisol and ACTH response (ESM Table 3, ESM Fig. 1).
Fig. 4 HRV spectral components. Data have been log-transformed (base 10) and are presented as means and SEM (shaded area). Data from hypoglycaemic clamps (a, c) and hyperglycaemic clamps (b, d) are shown. Target glucose levels $(\mathrm{mmol} / \mathrm{l})$ are indicated by the grey double-headed arrows. Solid lines, HI (BMI $\geq 27.0 \mathrm{~kg}$ / $\mathrm{m}^{2} ; n=15$ in a, c and $\left.n=14 \mathbf{b}, \mathbf{d}\right)$; dashed lines, LO (BMI <27.0 kg/ $\mathrm{m}^{2} ; n=11$ in $\mathbf{a}, \mathbf{c}$ and $n=13$ in $\left.\mathbf{b}, \mathbf{d}\right)$. Significance estimates refer to comparison of mean values of the indicated time period between groups $\mathrm{HI}$ and $\mathrm{LO}$ adjusted for the mean values during the euglycaemic phase (a) or the isoglycaemic phase (d): $* p<0.05$. Complete measurements are provided in ESM Table 2. Iso, isoglycaemic phase of hyperglycaemic clamp; Rec, recovery
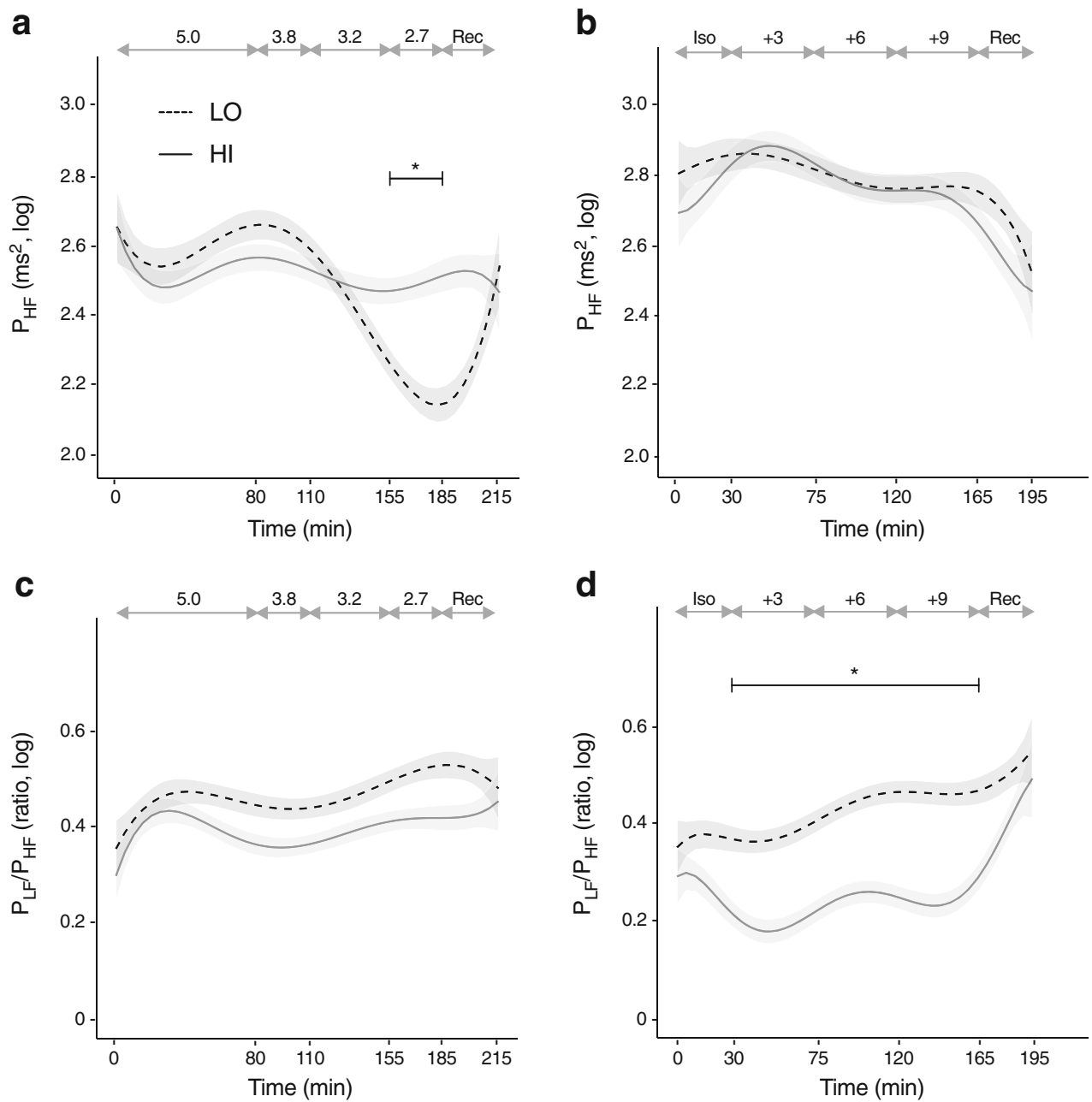


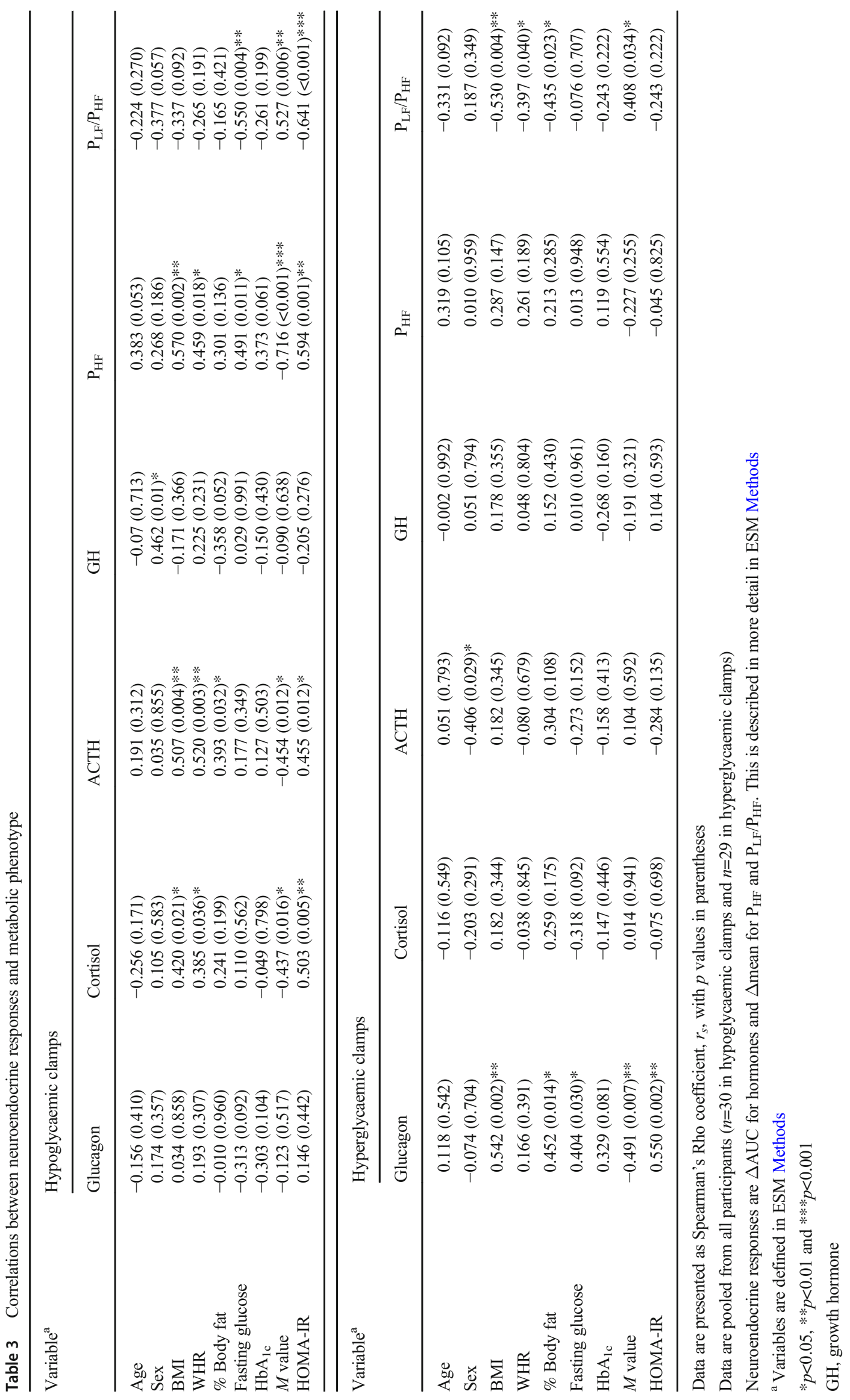


Table 4 Multilinear regressions of neuroendocrine responses vs metabolic phenotype

\begin{tabular}{|c|c|c|c|c|c|c|}
\hline \multirow[t]{2}{*}{ Variable $^{\mathrm{a}}$} & \multicolumn{4}{|c|}{ Hypoglycaemic clamps } & \multicolumn{2}{|c|}{ Hyperglycaemic clamps } \\
\hline & Cortisol & $\mathrm{ACTH}$ & $\mathrm{P}_{\mathrm{HF}}$ & $\mathrm{P}_{\mathrm{LF}} / \mathrm{P}_{\mathrm{HF}}$ & Glucagon $^{\mathrm{b}}$ & $\mathrm{P}_{\mathrm{LF}} / \mathrm{P}_{\mathrm{HF}}$ \\
\hline$R^{2}(p$ value $)$ & $0.188(0.061)$ & $0.208(0.043)^{*}$ & $0.484(0.002)^{* *}$ & $0.172(0.236)$ & $0.475(0.003)^{* *}$ & $0.146(0.151)$ \\
\hline BMI, $\beta$ ( $p$ value $)$ & $-0.022(0.931)$ & $-0.396(0.121)$ & $0.143(0.540)$ & $-0.051(0.864)$ & $0.480(0.029)^{*}$ & $-0.379(0.153)$ \\
\hline Fasting glucose, $\beta$ ( $p$ value) & NA & NA & $0.103(0.570)$ & $-0.261(0.259)$ & $-0.009(0.957)$ & NA \\
\hline$M$ value, $\beta$ ( $p$ value $)$ & $-0.449(0.085)$ & $-0.651(0.014)^{*}$ & $-0.527(0.031)^{*}$ & $0.178(0.546)$ & $-0.482(0.061)$ & $0.004(0.988)$ \\
\hline
\end{tabular}

Data are pooled from all participants ( $n=30$ in hypoglycaemic clamps and $n=29$ in hyperglycaemic clamps)

Neuroendocrine responses are $\triangle \mathrm{AUC}$ for hormones and $\Delta$ mean for $\mathrm{P}_{\mathrm{HF}}$ and $\mathrm{P}_{\mathrm{LF}} / \mathrm{P}_{\mathrm{HF}}$. This is described in more detail in ESM Methods

${ }^{\text {a }}$ Variables are defined in ESM Methods

${ }^{\mathrm{b}}$ Adjusted for $\mathrm{AUC}_{\text {Insulin }}$

${ }^{*} p<0.05$ and ${ }^{* *} p<0.01$

$\beta$, standardised coefficient; NA, not applicable/not analysed

In multilinear regressions, $M$ value was the strongest predictor for the ACTH and $\mathrm{P}_{\mathrm{HF}}$ responses, independent of BMI and other variables (Table 4). Excluding one outlier, the cortisol response had a positive association with $\triangle \mathrm{ESS}$, independent of BMI (ESM Table 3, ESM Fig. 1).

Hormonal response vs achieved glucose levels Figure 5 displays scatterplots of glucagon (Fig. 5a), cortisol (Fig. 5c) and ACTH (Fig. 5e) vs achieved mean glucose levels of each participants. The levels of all three hormones appear higher at the same glucose levels in HI vs LO. Although the group difference for glucagon was not significant during hypoglycaemia, $\operatorname{BMI}(p=$ 0.033 ) was associated with higher glucagon levels and $M$ value $(p=0.009)$ with lower glucagon levels in linear mixed models.

\section{Hyperglycaemic clamps}

Metabolism Glucose levels during hyperglycaemia were higher (but not significantly) in HI vs LO $(p=0.063)$ (Fig. $2 b)$. The GIR per kg FFM did not differ between the groups (Fig. 2h). Glycerol and NEFA levels were generally higher in HI vs LO but the decreases during hyperglycaemia were similar between groups (ESM Table 1).

Hormonal response Insulin and C-peptide were generally elevated in HI vs LO but the fold rise during hyperglycaemia was similar (Fig. 2d,f). The suppression of glucagon levels was attenuated during hyperglycaemia (median $\triangle \mathrm{AUC}-63.4 \%$ vs $-73.0 \% ; p=0.010)$ and overall levels were non-significantly higher ( $p=0.085$ ) in HI vs LO (Fig. 3b). Cortisol and ACTH levels did not differ between the groups; growth hormone levels were generally lower in HI vs LO but fell similarly during hyperglycaemia (Fig. 3d,f,h).

Haemodynamic measures and HRV Heart rate did not differ between the groups. Systolic and diastolic BP were overall higher during hyperglycaemia in $\mathrm{HI}$ vs LO, although the differences did not reach significance $(p=0.089$ and $p=$ 0.111 , respectively), and the trajectories during the clamp were similar (ESM Table 2).

None of the HRV indices differed significantly during the isoglycaemic phase. The $\mathrm{P}_{\mathrm{LF}} / \mathrm{P}_{\mathrm{HF}}$ ratio decreased during hyperglycaemia in HI but not in LO $(p=0.011)$ (Fig. 4b,d). Other HRV indices did not differ significantly between the groups (ESM Table 2).

Associations between neuroendocrine responses and metabolic phenotype Main results are displayed in Tables 3 and 4 . A scatterplot of $\triangle$ AUC for glucagon vs $M$ value is displayed in Fig. 5 h.

Obesity and insulin resistance measurements were positively correlated with less suppression of glucagon and more suppression of the $\mathrm{P}_{\mathrm{LF}} / \mathrm{P}_{\mathrm{HF}}$ response. In addition, fasting glucose was positively correlated with less glucagon suppression.

In multilinear regressions, BMI had the strongest association with the glucagon and $\mathrm{P}_{\mathrm{LF}} / \mathrm{P}_{\mathrm{HF}}$ response, although the associations were not statistically significant. When adjusting for insulin levels, the association between BMI and the glucagon response was significant however.

Hormonal response vs achieved glucose levels The overall glucagon levels were higher in $\mathrm{HI}$ vs LO at any given glucose level and the hyperglycaemia-induced suppression was less marked (Fig. 5g).

\section{Discussion}

In this study, we hypothesised that overweight and insulinresistant individuals have a higher setpoint for homeostatic regulation of circulating glucose levels than lean individuals. 
Fig. 5 Scatterplots of hormone levels vs glucose levels (a, c, e, g) and of $\triangle \mathrm{AUC}$ of hormones vs $M$ value $(\mathbf{b}, \mathbf{d}, \mathbf{f}, \mathbf{h})$. Hormone levels were measured at the end of each clamp stage vs mean glucometer glucose levels for the preceding 20 min during hypoglycaemic clamps (a, c, e) or hyperglycaemic clamps (g). $p$ values refer to estimates of group differences $(\mathbf{a}, \mathbf{e}, \mathbf{g})$ or interaction group $\times$ glucose $(\mathbf{c})$ in linear mixed models. Black circles, HI (BMI $\geq 27.0 \mathrm{~kg} / \mathrm{m}^{2}$; $n=15$ in a, c, e and $n=14$ in $\mathbf{g}$ ); white triangles, $\mathrm{LO}$ (BMI $<27.0$ $\mathrm{kg} / \mathrm{m}^{2} ; n=15$ in a, c, e, g); solid lines, exponential regression curve for HI; dotted lines, exponential regression curve for LO; black squares, $\triangle \mathrm{AUC}$ of the hypoglycaemic phase (80-185 $\min )(\mathbf{b}, \mathbf{d}, \mathbf{f} ; n=30)$ or the hyperglycaemic phase (30-165 $\min )(\mathbf{h} ; n=29)$ for all participants vs the $M$ value; $r_{s}$, Spearman's rho coefficient with corresponding $p$ value a

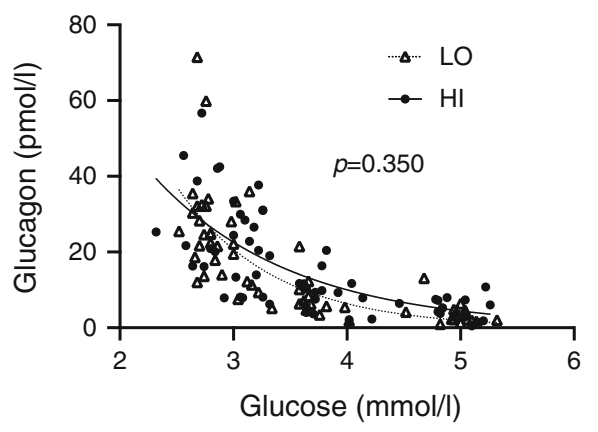

C

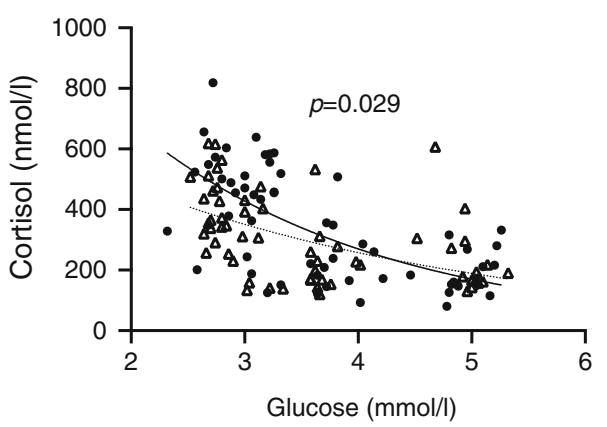

e
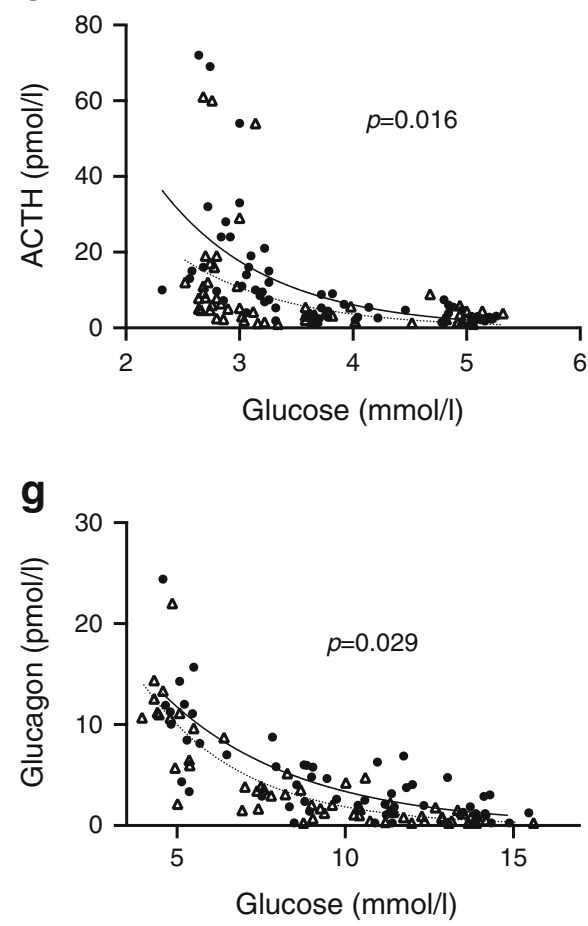

b

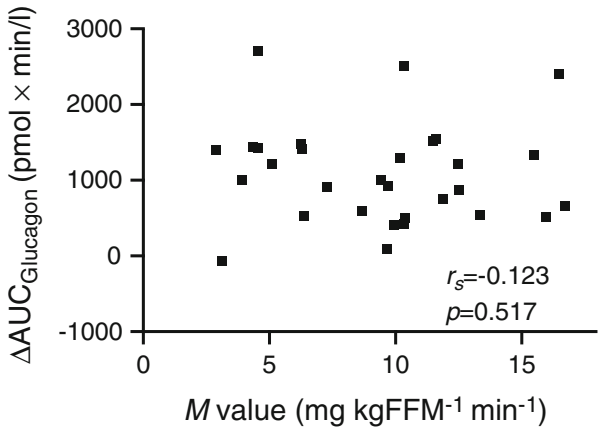

d

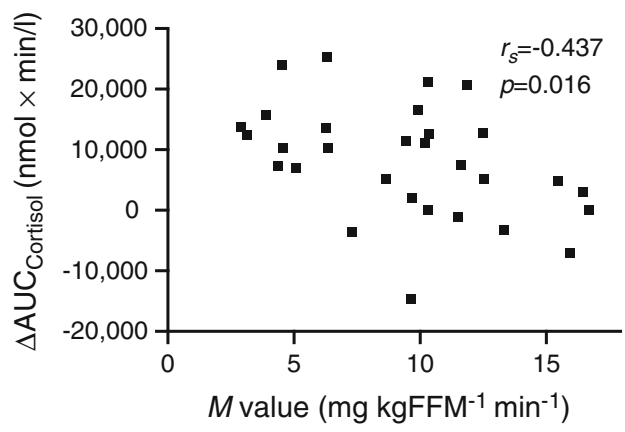

f

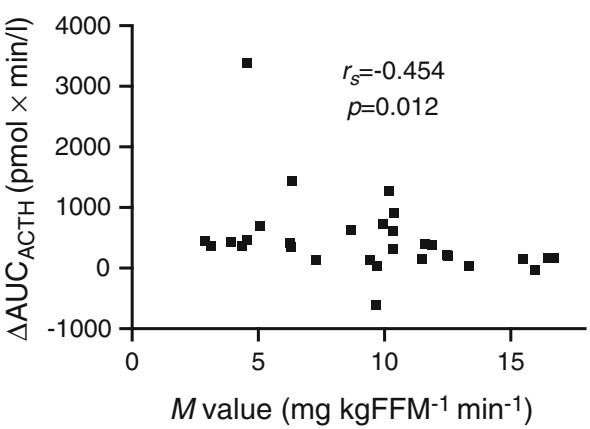

h

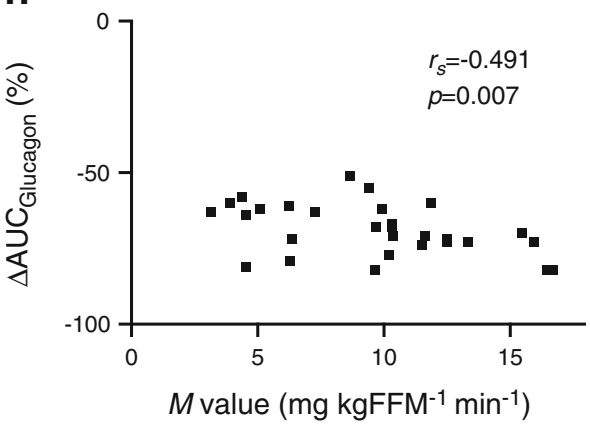

This would be reflected by faster or elevated counter-regulatory (i.e. insulin-antagonistic) responses to hypoglycaemia and, vice versa, by delayed or attenuated suppression of such responses during hyperglycaemia. Such findings could suggest a role for neuroendocrine dysregulation in the pathogenesis of type 2 diabetes. 


\section{Hypoglycaemia}

The main finding from the hypoglycaemic clamps was an augmented responsiveness of the cortisol axis to hypoglycaemia among overweight and insulin-resistant participants compared with lean and more insulin-sensitive participants. This appears to be of central origin, involving hypothalamic and pituitary functions, since ACTH and cortisol responses were similarly elevated in the HI vs LO group.

While the elevated hypoglycaemic symptom scores in HI vs LO did not reach significance, there were significant, BMIindependent, associations between symptoms and the cortisol axis response, suggesting a causal connection between perceived glucopenia and the augmented cortisol axis response in overweight individuals. Undoubtedly, the anatomical bridge for this connection would be within the CNS. Therefore, an increased CNS sensing of hypoglycaemia in obese individuals is possible but obviously not proven. This would be expected to raise the glycaemic 'setpoint' for cortisol axis responses but the magnitude of this shift could not be exactly defined due to the limited sample size and experimental design. However, as visualised in Fig. 5(c,e), a physiological cut-off for hypoglycaemia of $3 \mathrm{mmol} / \mathrm{l}$ appears to be shifted to about $3.3 \mathrm{mmol} / \mathrm{l}$ in the $\mathrm{HI}$ vs $\mathrm{LO}$ group with respect to ACTH and cortisol responses. Moreover, the fact that the enhanced cortisol axis response was inversely associated with the $M$ value, independent of BMI, points to a potential role in the development of insulin resistance. This may be further amplified by an increased local generation of cortisol in adipose tissue, and elevated tissue cortisol can be hypothesised to play a role in type 2 diabetes development [36]. Naturally, longitudinal studies of larger cohorts are needed to further support this hypothesis.

We evaluated sympathetic and parasympathetic nerve activity by HRV assessments. Given the increased symptoms of hypoglycaemia, an augmented sympathetic response in the overweight group might have been surmised. However, both obesity and, more clearly, insulin resistance was associated with a less dynamic ANS response to hypoglycaemia, characterised by less parasympathetic inhibition. Insulin resistance but not obesity was also associated with less sympathetic activation. Of interest, our group has previously reported that gastric bypass surgery was followed by an attenuated ANS response to hypoglycaemia [24]. We also reported that visceral adiposity [33] as well as insulin resistance [37] was associated with an increased sympathetic/parasympathetic ratio under normoglycaemic conditions. It should be acknowledged that HRV has limitations as a marker of ANS activity and has been questioned [38]. Although $\mathrm{P}_{\mathrm{HF}}$ supposedly reflects parasympathetic activity, the $\mathrm{P}_{\mathrm{LF}}$ represents both sympathetic and parasympathetic activity, and the $\mathrm{P}_{\mathrm{LF}} / \mathrm{P}_{\mathrm{HF}}$ ratio is utilised to reflect their relative contributions. Moreover, the importance and exact peripheral mechanisms of the two branches of the ANS with regards to glucose regulation is still uncertain [39-41]. The role of parasympathetic activity is particularly controversial. Apart from a proposed stimulation of glucagon secretion [40], our research group reported an unexpected rapid increase in insulin sensitivity following infusion of atropine [42], suggesting a paradoxical short-term effect by cholinergic pathways of the parasympathetic system to reduce peripheral glucose uptake. Thus, the attenuated inhibition of parasympathetic activity observed in overweight and insulin-resistant individuals during hypoglycaemia may potentially enhance the defence against hypoglycaemia and the maintenance of elevated everyday glucose levels. Catecholamine levels would be of interest in this context but they were presently not possible to analyse and were not considered as critical, since HRV assessments did not suggest any substantial group difference in sympathetic activity.

We found no differences in glucagon levels between groups during hypoglycaemia, nor were they associated with measures of obesity or insulin resistance. However, there were group differences in achieved glucose and insulin levels that may have underestimated differences in hormone responses. When adjusting for glucose levels in linear mixed models, both obesity and insulin resistance were indeed associated with significantly higher glucagon levels during hypoglycaemia. This is in concordance with a previous study showing augmented glucagon, ACTH and noradrenaline (norepinephrine) responses in obese individuals exposed to hypoglycaemia [7]. The more pronounced differences in their study may be due to use of the less specific RIA technique for glucagon measurement [32], greater BMI difference between groups and a younger and all-male study population.

The attenuation of the growth hormone response during hypoglycaemia in overweight individuals did not reach significance in our study, but has been observed in previous studies $[18,19]$.

\section{Hyperglycaemia}

During the hyperglycaemic clamps, overweight and insulinresistant participants displayed less suppression of glucagon than lean participants. This is in accordance with some previous studies [43-45] and may contribute to the development and progression of insulin resistance and potentially type 2 diabetes.

The cortisol responses to hyperglycaemia were highly variable between individuals and there were no consistent differences between groups. The initial decline in both groups is most likely explained by diurnal variations and the subsequent rise could represent a glucose-mediated stress response. A rise in cortisol levels after meals or an oral glucose load is wellestablished in previous work [46, 47]. 
We found markedly lower growth hormone levels during hyperglycaemia in overweight participants but glucosemediated inhibition was similar to that in lean participants, which is somewhat different to findings of a previous study [48].

The $\mathrm{P}_{\mathrm{LF}} / \mathrm{P}_{\mathrm{HF}}$ ratio rose during hyperglycaemia but was significantly lower in the overweight group indicative of a decreased sympathetic relative to parasympathetic activity. This resembles findings during hypoglycaemic conditions. Thus, the sympathetic response to acute hyperglycaemia and hyperinsulinaemia appears to be impaired in overweight insulin-resistant individuals, perhaps because of adaptation to slightly elevated glucose levels.

\section{Limitations}

There are some limitations to this study. First, as previously discussed, the minutely higher glucose and insulin levels achieved during clamps in overweight compared with lean participants may have affected insulin-antagonistic responses. Notably, this would mainly underestimate the differences in hormone levels found and, for completeness, we also adjusted for actual glucose levels in regression analyses. Second, while the elevated hormonal responses associated with obesity and insulin resistance are compatible with a hypothesised upward shift in glycaemic setpoint, our current data do not allow more than a very rough quantification of this shift. We plan analyses of data from pooled cohorts to address this. Third, the design may be underpowered to detect hypothetical effect sizes of interest. Fourth, several of the neuroendocrine alterations reported in this study were small in magnitude and the clinical implications need to be confirmed. Fifth, participants were recruited based on BMI rather than insulin resistance and the associations with neuroendocrine responses should be interpreted in the light of this. However, recruiting participants based on measures of insulin resistance or dysglycaemia (e.g. following OGTTs) would have markedly hampered feasibility. Finally, no adjustment for multiple comparisons was made. This was due to the exploratory nature of this work and also to biological interdependencies of the measured neurohormonal responses.

Overall, these findings are hypothesis-generating and need to be confirmed in larger studies.

\section{Conclusion}

This study demonstrates that overweight insulin-resistant individuals compared with lean individuals have increased central activation of the cortisol axis during hypoglycaemia, associated with more pronounced hypoglycaemic symptoms. This suggests an increased CNS-mediated response to hypoglycaemia. The finding that insulin resistance, more than obesity, is associated with the cortisol axis response is compatible with a causal role of the neurohormonal responses for the development of dysglycaemia and potentially type 2 diabetes. Furthermore, an attenuated suppression during hyperglycaemia and, to a lesser extent, an augmented glucagon rise during hypoglycaemia seem to be features of both insulin resistance and obesity. The anatomical sites, such as brain, pancreas or both, involved in this dysregulation remain to be elucidated in onward studies. By contrast, there is an attenuation of autonomic nerve responses to glucose fluctuations in overweight and insulin-resistant individuals that may reflect a less dynamic sympathetic and parasympathetic regulation, which in the long term may potentially contribute to dysglycaemia.

Taken together, altered insulin-antagonistic responses, including the cortisol axis, glucagon and ANS, in obese insulin-resistant individuals may contribute to the development of long-term dysglycaemia and, hypothetically, also type 2 diabetes. These perturbations may involve glucoregulatory functions of the brain shifting the 'glycaemic setpoint' for glucose-regulating hormones upwards. Our ongoing and future work will include individuals with type 2 diabetes and also the use of neuroimaging techniques to assess regional brain responses to hypo- and hyperglycaemia during diabetes development.

Supplementary Information The online version contains peer-reviewed but unedited supplementary material available at https://doi.org/10.1007/ s00125-020-05332-z.

Acknowledgements We are grateful for the diligent, meticulous and competent work by our study nurses A. Åhlander, S. Löfving, C. Woxberg and C. Almström (all Dept of Medical Sciences, Uppsala University, Sweden) in performing the clamp experiments. We are also grateful to F.A. Karlsson, Dept of Medical Sciences, Uppsala University, Sweden for providing valuable scientific advice. The graphical abstract was created using images obtained from BioRender.com with their permission.

Data availability Further information about data and resources will be provided upon request to the corresponding author.

Funding Open access funding provided by Uppsala University. This study was funded by grants from the Swedish Diabetes Foundation, the Ernfors Foundation, the NovoNordisk Foundation, EXODIAB strategic research program, Marie Sklodowska Curie Innovative Training Network TREATMENT (H2020-MSCA-ITN-721236) and ALF grants (Swedish Government research grants to the Uppsala University Hospital).

Authors' relationships and activities JWE has received honoraria, research funding and support from Astra Zeneca. The other authors declare that there are no relationships or activities that might bias, or be perceived to bias, this work.

Contribution statement MHL supervised experiments, assembled data, performed statistical analyses, designed graphs and wrote the manuscript. KA assisted in the study design, supervised experiments and revised the manuscript. UW performed HRV analyses, designed graphs and revised the manuscript. NA assisted in the study design and revised the manuscript. PGK analysed glucagon and lipolysis measures and revised the 
manuscript. MJP coordinated data management, gave advice and guidance on statistical aspects and revised the manuscript. JWE designed the study, supervised experiments, interpreted results and co-wrote the manuscript. All authors read and approved the final version of the manuscript. MHL is the guarantor of this work and, as such, had full access to all the data in the study and takes responsibility for the integrity of the data and the accuracy of the data analysis.

Open Access This article is licensed under a Creative Commons Attribution 4.0 International License, which permits use, sharing, adaptation, distribution and reproduction in any medium or format, as long as you give appropriate credit to the original author(s) and the source, provide a link to the Creative Commons licence, and indicate if changes were made. The images or other third party material in this article are included in the article's Creative Commons licence, unless indicated otherwise in a credit line to the material. If material is not included in the article's Creative Commons licence and your intended use is not permitted by statutory regulation or exceeds the permitted use, you will need to obtain permission directly from the copyright holder. To view a copy of this licence, visit http://creativecommons.org/licenses/by/4.0/.

\section{References}

1. Unger RH, Cherrington AD (2012) Glucagonocentric restructuring of diabetes: a pathophysiologic and therapeutic makeover. J Clin Invest 122(1):4-12. https://doi.org/10.1172/JCI60016

2. Stanley S, Moheet A, Seaquist ER (2019) Central Mechanisms of Glucose Sensing and Counterregulation in Defense of Hypoglycemia. Endocr Rev 40(3):768-788. https://doi.org/10. 1210/er.2018-00226

3. Farngren J, Ahren B (2019) Incretin-based medications (GLP-1 receptor agonists, DPP-4 inhibitors) as a means to avoid hypoglycaemic episodes. Metabolism 99:25-31. https://doi.org/ 10.1016/j.metabol.2019.06.016

4. Mitrakou A, Kelley D, Mokan M et al (1992) Role of reduced suppression of glucose production and diminished early insulin release in impaired glucose tolerance. N Engl J Med 326(1):2229. https://doi.org/10.1056/NEJM199201023260104

5. Bagger JI, Knop FK, Lund A, Holst JJ, Vilsboll T (2014) Glucagon responses to increasing oral loads of glucose and corresponding isoglycaemic intravenous glucose infusions in patients with type 2 diabetes and healthy individuals. Diabetologia 57(8):1720-1725. https://doi.org/10.1007/s00125-014-3264-2

6. Ichikawa R, Takano K, Fujimoto K et al (2019) Basal glucagon hypersecretion and response to oral glucose load in prediabetes and mild type 2 diabetes. Endocr J 66(8):663-675. https://doi.org/10. 1507/endocrj.EJ18-0372

7. Klement J, Kubera B, Eggeling J et al (2018) Effects of blood glucose on delay discounting, food intake and counterregulation in lean and obese men. Psychoneuroendocrinology 89:177-184. https://doi.org/10.1016/j.psyneuen.2018.01.014

8. Shamoon H, Friedman S, Canton C, Zacharowicz L, Hu M, Rossetti L (1994) Increased epinephrine and skeletal muscle responses to hypoglycemia in non-insulin-dependent diabetes mellitus. J Clin Invest 93(6):2562-2571. https://doi.org/10.1172/ JCI1 17267

9. Weaver JU, Kopelman PG, McLoughlin L, Forsling ML, Grossman A (1993) Hyperactivity of the hypothalamo-pituitaryadrenal axis in obesity: a study of ACTH, AVP, beta-lipotrophin and cortisol responses to insulin-induced hypoglycaemia. Clin
Endocrinol 39(3):345-350. https://doi.org/10.1111/j.1365-2265. 1993.tb02375.x

10. Lundqvist MH, Almby K, Abrahamsson N, Eriksson JW (2019) Is the Brain a Key Player in Glucose Regulation and Development of Type 2 Diabetes? Front Physiol 10:457. https://doi.org/10.3389/ fphys.2019.00457

11. Dunning BE, Gerich JE (2007) The role of alpha-cell dysregulation in fasting and postprandial hyperglycemia in type 2 diabetes and therapeutic implications. Endocr Rev 28(3):253-283. https://doi. org/10.1210/er.2006-0026

12. Coiro V, Passeri M, d'Amato L et al (1988) Glucagon response to insulin-induced hypoglycemia in obese men. Horm Metab Res 20(10):656-657. https://doi.org/10.1055/s-2007-1010910

13. Lassmann V, Cabrerizzo Garcia L, Vialettes B, Vague P (1985) Impaired pancreatic polypeptide response to insulin hypoglycemia in obese subjects. Horm Metab Res 17(12):663-666. https://doi. org/10.1055/s-2007-1013638

14. Bischof MG, Ludwig C, Hofer A et al (2000) Hormonal and metabolic counterregulation during and after high-dose insulin-induced hypoglycemia in diabetes mellitus type 2. Horm Metab Res 32(10): 417-423. https://doi.org/10.1055/s-2007-978664

15. Gylfe E (2016) Glucose control of glucagon secretion-'There's a brand-new gimmick every year'. Ups J Med Sci 121(2):120-132. https://doi.org/10.3109/03009734.2016.1154905

16. Abraham SB, Rubino D, Sinaii N, Ramsey S, Nieman LK (2013) Cortisol, obesity, and the metabolic syndrome: a cross-sectional study of obese subjects and review of the literature. Obesity (Silver Spring) 21(1):E105-E117. https://doi.org/10.1002/oby. 20083

17. Incollingo Rodriguez AC, Epel ES, White ML, Standen EC, Seckl JR, Tomiyama AJ (2015) Hypothalamic-pituitary-adrenal axis dysregulation and cortisol activity in obesity: A systematic review. Psychoneuroendocrinology 62:301-318. https://doi.org/10.1016/j. psyneuen.2015.08.014

18. Scacchi M, Pincelli AI, Cavagnini F (1999) Growth hormone in obesity. Int J Obes Relat Metab Disord 23(3):260-271. https://doi. org $/ 10.1038 /$ sj.ijo. 0800807

19. Rasmussen $\mathrm{MH}$ (2010) Obesity, growth hormone and weight loss. Mol Cell Endocrinol 316(2):147-153. https://doi.org/10.1016/j. mce.2009.08.017

20. Benichou T, Pereira B, Mermillod M et al (2018) Heart rate variability in type 2 diabetes mellitus: A systematic review and metaanalysis. PLoS One 13(4):e0195166. https://doi.org/10.1371/ journal.pone.0195166

21. Kim JA, Park YG, Cho KH et al (2005) Heart rate variability and obesity indices: emphasis on the response to noise and standing. $\mathrm{J}$ Am Board Fam Pract 18(2):97-103. https://doi.org/10.3122/jabfm. 18.2.97

22. Saito I, Hitsumoto S, Maruyama K et al (2015) heart rate variability, insulin resistance, and insulin sensitivity in japanese adults: the toon health study. J Epidemiol 25(9):583-591. https://doi.org/10.2188/ jea.JE20140254

23. Deem JD, Muta K, Scarlett JM, Morton GJ, Schwartz MW (2017) How should we think about the role of the brain in glucose homeostasis and diabetes? Diabetes 66(7):1758-1765. https://doi.org/10. 2337/dbi16-0067

24. Abrahamsson N, Borjesson JL, Sundbom M, Wiklund U, Karlsson FA, Eriksson JW (2016) Gastric Bypass Reduces Symptoms and Hormonal Responses in Hypoglycemia. Diabetes 65(9):26672675. https://doi.org/10.2337/db16-0341

25. Guldstrand M, Ahren B, Wredling R, Backman L, Lins PE, Adamson U (2003) Alteration of the counterregulatory responses to insulin-induced hypoglycemia and of cognitive function after massive weight reduction in severely obese subjects. Metabolism 52(7):900-907. https://doi.org/10.1016/s0026-0495(03)00103-3 
26. Norjavaara E, Ericsson H, Sjoberg F et al (2012) Glucokinase activators AZD6370 and AZD1656 do not affect the central counterregulatory response to hypoglycemia in healthy males. $\mathrm{J}$ Clin Endocrinol Metab 97(9):3319-3325. https://doi.org/10.1210/ jc.2012-1496

27. DeFronzo RA, Tobin JD, Andres R (1979) Glucose clamp technique: a method for quantifying insulin secretion and resistance. Am J Phys 237(3):E214-E223. https://doi.org/10.1152/ajpendo. 1979.237.3.E214

28. Zhang Y, Chi J, Wang W et al (2015) Different effects of two dipeptidyl peptidase-4 inhibitors and glimepiride on beta-cell function in a newly designed two-step hyperglycemic clamp. J Diabetes 7(2):213-221. https://doi.org/10.1111/1753-0407.12175

29. Deary IJ, Hepburn DA, MacLeod KM, Frier BM (1993) Partitioning the symptoms of hypoglycaemia using multi-sample confirmatory factor analysis. Diabetologia 36(8):771-777. https:// doi.org/10.1007/BF00401150

30. McAulay V, Deary IJ, Ferguson SC, Frier BM (2001) Acute hypoglycemia in humans causes attentional dysfunction while nonverbal intelligence is preserved. Diabetes Care 24(10):1745-1750. https:// doi.org/10.2337/diacare.24.10.1745

31. Berntson GG, Bigger JT Jr, Eckberg DL et al (1997) Heart rate variability: origins, methods, and interpretive caveats. Psychophysiology 34(6):623-648. https://doi.org/10.1111/j.14698986.1997.tb02140.x

32. Wewer Albrechtsen NJ, Hartmann B, Veedfald S et al (2014) Hyperglucagonaemia analysed by glucagon sandwich ELISA: nonspecific interference or truly elevated levels? Diabetologia 57(9):1919-1926. https://doi.org/10.1007/s00125-014-3283-z

33. Lindmark S, Lonn L, Wiklund U, Tufvesson M, Olsson T, Eriksson JW (2005) Dysregulation of the autonomic nervous system can be a link between visceral adiposity and insulin resistance. Obes Res 13(4):717-728. https://doi.org/10.1038/oby.2005.81

34. Schmid SM, Hallschmid M, Jauch-Chara K, Bandorf N, Born J, Schultes B (2007) Sleep loss alters basal metabolic hormone secretion and modulates the dynamic counterregulatory response to hypoglycemia. J Clin Endocrinol Metab 92(8):3044-3051. https:// doi.org/10.1210/jc.2006-2788

35. Ahren B, Schweizer A, Dejager S et al (2009) Vildagliptin enhances islet responsiveness to both hyper- and hypoglycemia in patients with type 2 diabetes. J Clin Endocrinol Metab 94(4):12361243. https://doi.org/10.1210/jc.2008-2152

36. Tomlinson JW, Finney J, Gay C, Hughes BA, Hughes SV, Stewart PM (2008) Impaired glucose tolerance and insulin resistance are associated with increased adipose 11 beta-hydroxysteroid dehydrogenase type 1 expression and elevated hepatic 5alpha-reductase activity. Diabetes 57(10):2652-2660. https://doi.org/10.2337/ db08-0495

37. Svensson MK, Lindmark S, Wiklund U et al (2016) Alterations in heart rate variability during everyday life are linked to insulin resistance. A role of dominating sympathetic over parasympathetic nerve activity? Cardiovasc Diabetol 15:91. https://doi.org/10. 1186/s12933-016-0411-8

38. Perini R, Veicsteinas A (2003) Heart rate variability and autonomic activity at rest and during exercise in various physiological conditions. Eur J Appl Physiol 90(3-4):317-325. https://doi.org/10. 1007/s00421-003-0953-9

39. Rodriguez-Diaz R, Caicedo A (2014) Neural control of the endocrine pancreas. Best Pract Res Clin Endocrinol Metab 28(5):745756. https://doi.org/10.1016/j.beem.2014.05.002

40. Taborsky GJ Jr, Mundinger TO (2012) Minireview: The role of the autonomic nervous system in mediating the glucagon response to hypoglycemia. Endocrinology 153(3):1055-1062. https://doi.org/ 10.1210/en.2011-2040

41. Yi CX, la Fleur SE, Fliers E, Kalsbeek A (2010) The role of the autonomic nervous liver innervation in the control of energy metabolism. Biochim Biophys Acta 1802(4):416-431. https://doi.org/10. 1016/j.bbadis.2010.01.006

42. Svensson MK, Jansson PA, Persson AL, Sjostrand M, Eriksson JW (2011) Atropine improves insulin sensitivity in both lean and abdominally obese subjects. J Clin Endocrinol Metab 96(11): E1843-E1847. https://doi.org/10.1210/jc.2011-0669

43. Solomon TP, Knudsen SH, Karstoft K, Winding K, Holst JJ, Pedersen BK (2012) Examining the effects of hyperglycemia on pancreatic endocrine function in humans: evidence for in vivo glucotoxicity. J Clin Endocrinol Metab 97(12):4682-4691. https://doi.org/10.1210/jc.2012-2097

44. Vilsboll T, Krarup T, Madsbad S, Holst JJ (2002) Defective amplification of the late phase insulin response to glucose by GIP in obese Type II diabetic patients. Diabetologia 45(8):1111-1119. https://doi.org/10.1007/s00125-002-0878-6

45. Bonora E, Moghetti P, Cacciatori V et al (1990) Plasma concentrations of glucagon during hyperglycemic clamp with or without somatostatin infusion in obese subjects. Acta Diabetol Lat 27(4): 309-314. https://doi.org/10.1007/bf02580935

46. Follenius M, Brandenberger G, Hietter B (1982) Diurnal cortisol peaks and their relationships to meals. J Clin Endocrinol Metab 55(4):757-761. https://doi.org/10.1210/jcem-55-4-757

47. Reynolds RM, Walker BR, Syddall HE, Whorwood CB, Wood PJ, Phillips DI (2001) Elevated plasma cortisol in glucose-intolerant men: differences in responses to glucose and habituation to venepuncture. J Clin Endocrinol Metab 86(3):1149-1153. https:// doi.org/10.1210/jcem.86.3.7300

48. Bonora E, Moghetti P, Zenere M et al (1990) Plasma concentrations of growth hormone during hyperglycemic clamp with or without somatostatin infusion in obese subjects. J Clin Endocrinol Metab 70(6):1732-1734. https://doi.org/10.1210/jcem-70-6-1732

Publisher's note Springer Nature remains neutral with regard to jurisdictional claims in published maps and institutional affiliations. 